\title{
A gravidez na adolescência produzindo evasão escolar: um exame bibliográfico
}

\author{
Adolescent pregnancy leading to school dropout: a bibliographic examination
}

Embarazo adolescente que conduce al abandono escolar: un examen bibliográfico

Lázaro Saluci Ramos ${ }^{1 *}$, Renata dos Santos Ribeiro Guzman², Hilka Quinelato², Bethânia Fricks Jordão Belonia Mota ${ }^{3}$, Claudia Márcia Fricks Jordão Belonia Terra ${ }^{3}$, Fernanda Baiense de Almeida Paes $^{3}$, Maria Aparecida Terra Tonon ${ }^{3}$, Chirlene Wandermurem Louzada ${ }^{3}$, Jacira Marvila Batista Viana $^{3}$, Simone Fernandes de França ${ }^{3}$.

\section{RESUMO}

Objetivo: Objetiva-se na presente revisão abordar, aglomerando desenlaces, o problema da gravidez na adolescência como causadora de evasão escolar nas escolas públicas brasileiras, a fim de introduzir novas táticas e políticas públicas que visem garantir o direito a educação nos casos em questão. Revisão bibliográfica: A bibliografia atual aponta métodos de desenvolvimento e adequação do ambiente escolar para introduzir no campo acadêmico facilitadoras simples e complexas, todavia, o problema da gravidez na adolescência causando evasão escolar é também um problema de saúde pública. A ideia é levar a amostra de dados já publicados visando garantir que saúde e educação devem unir forças na busca por soluções viáveis. O espectro socioeconômico quando levado em conta, aponta a desigualdade social e o difícil acesso à informação, como causadores do óbice, além da omissão estatal. Considerações finais: Entende-se, portanto, que instruir somente, não é suficiente para alcançar resultados satisfatórios, mas atentar para os problemas causados pela desigualdade social e inovar com políticas contemporâneas garantindo os direitos básicos de educação e saúde.

Palavras-chave: Gravidez na adolescência, Serviços de saúde materna, Promoção da saúde.

\begin{abstract}
Objective: The objective of this review is to address, by agglomerating outcomes, the problem of teenage pregnancy as a cause of school dropout in Brazilian public schools, in order to introduce new public tactics and policies that aim to guarantee the right to education in the cases in question. Bibliographic review: The current bibliography points out methods of development and adaptation of the school environment to introduce simple and complex facilitators in the academic field, however, the problem of teenage pregnancy causing school dropout is also a public health problem. The idea is to take the sample of data already published in order to ensure that health and education should join forces in the search for viable solutions. The socioeconomic spectrum, when taken into account, points to social inequality and the difficult access to information, as causing the obstacle, in addition to state omission. Final considerations: It is understood, therefore, that instructing alone is not enough to achieve satisfactory results, but to pay attention to the problems caused by social inequality and to innovate with contemporary policies guaranteeing the basic rights of education and health.
\end{abstract}

Key words: Adolescent pregnancy, Maternal health services, Health promotion.

${ }^{1}$ Faculdade Multivix (MULTIVIX), Cachoeiro de Itapemirim - ES. *E-mail: lazaro321123@gmail.com

${ }^{2}$ Facultad Interamericana de Ciencias Sociales (FICS), Assunção - Paraguai.

${ }^{3}$ Faculdade Vale do Cricaré (FVC), São Mateus - ES. 


\section{RESUMEN}

Objetivo: El objetivo de esta revisión es abordar, mediante la aglomeración de resultados, el problema del embarazo adolescente como causa del abandono escolar en las escuelas públicas brasileñas, con el fin de introducir nuevas tácticas y políticas públicas que tengan como objetivo garantizar el derecho a la educación en los casos en cuestión. Revisión bibliográfica: La bibliografía actual señala métodos de desarrollo y adaptación del entorno escolar para introducir facilitadores simples y complejos en el campo académico, sin embargo, el problema del embarazo adolescente que causa el abandono escolar también es un problema de salud pública. La idea es tomar la muestra de datos ya publicados para garantizar que la salud y la educación se unan en la búsqueda de soluciones viables. El espectro socioeconómico, cuando se tiene en cuenta, apunta a la desigualdad social y al difícil acceso a la información, como causante del obstáculo, además de la omisión estatal. Consideraciones finales: Se entiende, por lo tanto, que la instrucción por sí sola no es suficiente para lograr resultados satisfactorios, sino para prestar atención a los problemas causados por la desigualdad social e innovar con políticas contemporáneas que garanticen los derechos básicos de educación y salud.

Palabras clave: Embarazo adolescente, Servicios de salud materna, Promoción de la salud.

\section{INTRODUÇÃO}

O problema social da gravidez na adolescência tem sido amplamente discutido no decorrer dos anos, a grande preocupação gira em torno das dificuldades dispensadas as jovens mães na criação dos seus filhos, além da castração de fases necessárias da vida para a formação da mulher. Dentre as inúmeras dificuldades que nascem com a responsabilidade de ser mãe muito cedo, a garantia do direito a educação se tornou um dos problemas mais graves, já que em quase todos os casos a mãe adolescente não teve tempo para concluir a vida acadêmica na educação básica, e em grande parte dos casos ela decide abandonar os estudos para exercer a maternidade (CASTRO ABC, et al., 2018).

Social e historicamente, construiu-se o estigma de que a mãe é quem deve criar os filhos enquanto o pai provém os recursos financeiros. Com base nesse pensamento, a pressão para que a mulher seja a cuidadora do lar persiste nos tempos atuais, fazendo com que muitas jovens que engravidam precocemente abandonem os estudos ou desistam da vida acadêmica após concluir o ensino médio. O machismo estrutural se tornou mais um agravante e causador da evasão escolar de mães adolescentes, até uma pressão social, considerando que boa parte das famílias brasileira são conservadores e levam em consideração o julgamento social, buscando evitar o máximo o julgamento social, ou tentando apaziguar situações moralmente rejeitadas (CHACHAM AS, et al., 2012).

Em alguns casos, o problema se desdobra para questão socioeconômica. Muitas adolescentes acabam abandonando os estudos para buscar atender as necessidades econômicas da família. Muito comum em casos onde o pai da criança não é presente ou não dispõe de meios econômicos suficientes para o sustento da casa. Abandonar os estudos e ingressar precocemente no mercado de trabalho acaba sendo a única solução, já que as políticas sociais do Estado que visam garantir a vida escolar dessa população é muito escassa, e os programas sociais de distribuição de renda não atendem completamente as necessidades das classes mais baixas (CHACHAM AS, et al., 2012).

O combate a gravidez na adolescência é uma questão nitidamente de saúde pública, contudo, aonde que o público alvo pode ser atingido? Após a ampliação dos programas que buscaram a democratização do acesso à educação e do ensino, o local mais apropriado para alcançar o público alvo é a escola. Unir saúde e educação pública para alcançar os objetivos de reduzir, e no futuro extinguir, a gravidez precoce indesejada, mostrou-se um caminho atrativo e promissor. As políticas públicas tendem sempre a serem desenvolvidas com métodos de prevenção, já que o objetivo é garantir o direito de todos, e colaborar para que os efeitos dos que já foram vítimas do problema, sejam o mais brando possível (SOUSA CRO, et al., 2018).

A Organização Mundial da saúde divulgou dados de um levantamento realizado entre 2010 e 2015 que mostra que de cada 100 mil meninas brasileiras de 15 a 19 anos, 68,4 tiveram uma gravidez precoce. 
Inclusive, o índice brasileiro supera os números da média latino-americana que é de 65,5 filhos de mães adolescentes para cada 100 mil. Apesar dos números apresentarem queda nos últimos 10 anos, o Brasil ainda está bem distante de Países desenvolvidos como Estados Unidos que tem 22,3 nascimentos para cada 100 mil adolescentes e Canadá, com 11,3 nascimentos. Com relação a dados coletados na América do Sul, o Chile apresenta os melhores números, com 52,7 nascimentos para cada 100 mil (OMS, 2018).

Um estudo da fundação Abrinq apontou que 30\% das jovens mães com até 19 anos não terminaram sequer o ensino fundamental. Os efeitos da gravidez precoce na educação são desastrosos, já que com os dados atuais mostra-se um dos principais problemas causadores de evasão escolar no Brasil. Em regiões como o Norte e o Nordeste os resultados são ainda mais assustadores, já que cerca de $35 \%$ das adolescentes mães não concluíram o ensino fundamental, fator que indica a pobreza como um dos agravantes do problema social, já que se tratam das duas regiões mais pobres do País (SOUSA CRO, 2018).

O objetivo desta revisão é apontar métodos e resultados de pesquisas que colaborem com a redução da evasão escolar, com base na união de saúde e educação pública, garantindo que o problema social da gravidez na adolescência deixe de ser um fator potencializador do abandono escolar por jovens e adolescentes. Ainda apontar políticas que possam ser inseridas nas prioridades públicas afim de garantir que as jovens que já são mães e que não conseguiram concluir a vida acadêmica, possam retornar as casas de educação pública e no futuro alcançarem os objetivos que traçaram para a vida adulta. Esta revisão também cuidará de problemas sociais graves, como o machismo estrutural, que é um dos principais distanciadores de mulheres das novas realidades socioeconômicas, que levam a independência financeira e afetiva.

\section{REVISÃo BIBLIOGRÁFICA}

Historicamente a figura feminina foi vítima de distorção quanto a sua capacidade de subsistir e garantir a própria segurança. Os homens tornaram a sociedade extremamente hostil para as mulheres, uma forma de garantir a dependência feminina de uma figura masculina, o que por muitos milênios vem alimentando o machismo estrutural, que é o preconceito invisível contra pessoas do sexo feminino. Tornar a mulher vulnerável foi a forma mais fácil de trancafiá-la a padrões morais e reduzir os direitos das mulheres frente ao leque de possibilidades que sempre foram dadas aos homens (CARVALHO MP, 2003).

A independência da mulher, mesmo se tratando de um progresso iniciado há séculos, ainda é recente frente aos milhares de anos de opressão. Legislações pretéritas denunciam o machismo das sociedades antigas, o poder masculino sobre as mulheres era institucional. No Brasil, mesmo quando já era permitido que mulheres frequentassem o campo acadêmico, era muito difícil obter a aceitação da família. Os direitos reais de independência feminina foram consagrados em 1966, quando passou a vigorar o Pacto Internacional de Direitos Civis e Políticos, que outorgou as mulheres os mesmos direitos que eram consagrados aos homens (PRÁ JR e EPPING L, 2012).

Quando enfim, a mulher conseguiu chegar à escola, os empecilhos e dificuldades foram crescendo, como forma de boicotar a liberdade e as lutas por igualdade de gênero. Até os tempos atuais as mulheres ainda possuem imensas dificuldades de se sustentarem no campo acadêmico em algumas situações, dificuldades estas que não são postas aos homens. A gravidez na adolescência é um exemplo clássico de distanciamento da mulher da sociedade. A clássica religiosa que cobra posturas morais de uma mulher grávida, como o casamento ou minimamente um compromisso firmado, retira de meninas o direito a adolescência saudável e plena. Negar o conhecimento, deixar de inserir políticas de combate a gravidez na adolescência ou políticas estruturais para que essas mães jovens possam continuar frequentando a escola, é uma forma de negar o direito constitucional a educação, consagrado em 1988 (VIEIRA MC e CRUZ KN, 2017).

A gravidez precoce também é causadora de transtornos mentais como depressão e ansiedade, mais um dado que amplia a responsabilidade da saúde pública e torna clara a necessidade de uma união entre os campos públicos. Considerando que a adolescência é compreendida no espaço de tempo dos 10 aos 19 anos, é notório que o período está englobando seres que frequentam o ensino fundamental e médio. Instruir para prevenir é uma tática essencial, já que a grande maioria dos adolescentes tratam o sexo e a sexualidade como pornografia, e não adquirem conhecimentos enriquecedores acerca do assunto (MENESES C, et al., 2008). 
A educação sexual pode ser utilizada como instrumento de ampliar o conhecimento, desenvolver táticas de prevenção e reduzir os dados de gravidez precoce no Brasil. A escola funciona como grande centro de inovação e transmissor de conhecimento científico. O aluno quando recebe a informação na escola, tem uma probabilidade maior de absorver e construir conceitos sobre aquilo do que dispensar ou levar em consideração informações recebidas fora do ambiente escolar. Os riscos e as consequências de uma gravidez precoce, ainda não foram colocadas as claras aos jovens brasileiros (EW RAS, et al., 2017)

\section{Políticas públicas de educação e saúde}

As políticas públicas de educação e saúde são muito úteis quando inseridas em meios com problemas sociais identificados que atingem usuários de ambas as áreas. As casas de saúde pública ou as escolas, são ambientes que comportam cidadãos vulneráveis socialmente, e isso faz com que um dos objetivos das políticas de instrução, que é reunir o maior número de pessoas que se enquadram no público alvo, seja realizado. Com as inserções tecnológicas e o desenvolvimento científico, as adaptações ficaram mais perfeccionistas e as implantações de políticas públicas foram facilitadas (CARDOSO MLM, et al., 2017).

As disciplinas da área da saúde utilizam pouco espaço para advertências e instruções quanto a necessidade do conhecimento do sexo e da sexualidade. Conhecer o próprio corpo, as próprias estruturas e ser advertido acerca das possíveis consequências de atos não pensados, são realidades bem distantes da grade curricular nacional. O conservadorismo social é um empecilho constante e uma barreira dramática para alcançar adolescentes desinstruídos quanto ao próprio corpo (DINIS N e ASINELLI-LUZ A, 2007).

O conceito de educação sexual também é ultrapassado e carregado de rótulos irreais. A ideia de que adolescentes vão aprender a fazer sexo na escola ou que vão ficar atraídos pela ideia quando o assunto for abordado, é uma das piores conclusões possíveis, quando que adolescentes cada dia mais ficam grávidas devido à ausência de instrução correta. A ideia gira em torno do conhecimento do próprio corpo, do conhecimento da anatomia humana, já que em alguns casos meninas de apenas 9 anos já menstruam, e não encontram dentro do lar um ambiente saudável e instrutivo, na grande maioria dos casos, as famílias não aportam conhecimento suficiente para lidar com tais situações (DINIS N e ASINELLI-LUZ A, 2007).

As doenças sexualmente transmissíveis também implicam um enorme problema para a saúde pública e que podem ser alcançados, à fim de prevenir e combater, nas escolas. Um projeto de lei da deputada federal Alice Portugal propôs a criação do Programa de Orientação Sexual, de Prevenção das Doenças Sexualmente Transmissíveis e do Uso de Drogas nas escolas. O projeto que começou tramitar na Câmara dos Deputados no ano de 2007 foi arquivado e voltou a tramitar no ano de 2019. A autora do projeto fez a defesa do mesmo alegando que a escola é um espaço pronto para este trabalho, já que é nesse espaço que o desenvolvimento intelectual, as dúvidas e incertezas, estão constantemente em discussão (CÂMARA DOS DEPUTADOS, 2007).

O projeto propõe que: Art. 1‥ No intuito da orientação das novas gerações, a União, os Estados e o Distrito Federal, concorrentemente, proporcionarão meios de implementação nos estabelecimentos de ensino de primeiro e segundo graus dos respectivos Sistemas de Ensino, do Programa de Orientação Sexual, de Prevenção das Doenças Sexualmente Transmissíveis e de Prevenção do uso de Drogas. Parágrafo único: O programa de que trata este artigo deverá realizar-se deforma multidisciplinar e contínua, de acordo com a idade e as necessidades de cada turma. Art. 2․ Os Sistemas de Ensino oferecerão Programas de Formação aos seus educadores, que assim optarem, em caráter contínuo e sistemático, com uma visão multidisciplinar. Art. $3^{\circ}$. Esta Lei entra em vigor na data de sua promulgação (BRASIL, 2007).

Inúmeras são as finalidades de incluir políticas públicas de saúde dentro das escolas. À fim de garantir uma defesa coesa da instrução sexual nas escolas, a prevenção de doenças sexualmente transmissíveis, a redução dos alarmantes dados de gravidez na adolescência e também o combate ao abuso sexual de menores. $\mathrm{O}$ abuso sexual de menores, em ampla maioria dos casos, acontece no seio familiar ou por pessoas próximas que gozam da confiança da família. Muitas das vítimas de abuso sexual não sabem sequer o que é 
sexo e que aquela abordagem é errada. Falar sobre sexo com uma vítima pode ser o sopro necessário para que ela denuncie ou encontre a pessoa certa para pedir ajudar (VERAS T, 2010).

O ambiente escolar pode ser mais bem frequentado por profissionais da saúde pública afim de estabelecer uma conexão maior entre o aluno e os cuidados necessários com a própria saúde. As disciplinas da área da saúde podem ser a porta para que essa necessidade seja despertada no discente, abrindo mais uma possibilidade que é o adolescente, desde muito cedo, estar atento aos cuidados com o corpo. Quando o ambiente escolar é munido de estratégias de segurança para o aluno, as chances de ele abandonar aquele ambiente são menores. Todas as políticas públicas aplicadas na escola, colaboram para evitar a evasão escolar, já que abandonar o ambiente acadêmico está intimamente ligado ao mal estar que a escola pode produzir (FAIAL LCM, et al., 2019).

\section{Evasão escolar e o conservadorismo social}

O conservadorismo social é um dos maiores produtores de preconceitos contra mulheres na sociedade contemporânea. A ideia de que a mulher não é capaz de existir sem o amparo de um homem, foi distribuída historicamente nas sociedades europeias, que foram responsáveis por colonizações em quase todos os continentes. Algumas culturas asiáticas, baseadas nas crenças islâmicas, também distribuíram a ideia de que a mulher não é um ser humano, mas um produto. Toda influência machista predominante ao longo dos milênios, esboçou uma ideia de mulher inferior ao homem (FACCHINI R e SíVORI H, 2017).

A ideia de que o homem é o chefe da família e a esposa é a responsável pelo bom andamento do lar, afasta as possibilidades de independência feminina. As mulheres podem até estar alcançando em maior número as universidades, mas não alcançam em maior número os altos cargos das grandes empresas, os cargos mais altos dos três poderes ou a chefia de grandes corporações. Isso se dá pela falsa ideia distribuída no tempo, de que a mulher é inferior intelectualmente que o homem, que ela existe apenas para servir e não para ter prazer ou tomar suas próprias decisões (FACCHINI R e SíVORI H, 2017).

A gravidez na adolescência, quase em sua totalidade, acontece no período que a adolescente é estudante. A responsabilidade de prover o sustento de uma criança não afasta somente a menina do ambiente escolar, mas acaba levando, em escassas situações, o menino ao mercado de trabalho precocemente, o que por consequência pode acabar afastando-o também do ambiente educacional. Atitudes como essas geralmente são incentivadas pelas famílias, que também não encontram outra alternativa para prover o sustento de mais um membro (SOUSA CRO, 2018).

Ter uma filha mãe solteira é um grande tabu para os pais e uma arma maléfica quando é abordado o julgamento social. As críticas e castrações que a mulher sofre quando é mãe antes do casamento, além de gerar inúmeros transtornos causa outros efeitos no campo físico. O distanciamento social causando a solidão da mulher, reduzindo-a a objeto, promove um afastamento de centros movimentados, como a escola, por exemplo. A influência que os alunos de uma escola recebem de pais conservadores, faz com que discursos agressivos sejam reproduzidos em sala de aula, isso acaba afastando a nova realidade de uma mãe precoce da realidade acadêmica, considerando que o ser humano tende a abandonar ambientes que the causem sofrimento (PICCININI CA, et al., 2007).

A constituição de 1988 foi a primeira a consagrar igualdade entre os gêneros masculino e feminino. $O$ artigo mais importante versa sobre inúmeros direitos e deveres do cidadão e a postura do Estado com relação as diferenças. Também, a carta magna busca reduzir os efeitos do machismo histórico na sociedade brasileira, reduzir a desequiparação salarial entre os gêneros e a desigualdade ética. $O$ inciso que trata do assunto é o I, e é uma forma da lei reconhecer que existe desigualdade. Além do caput que versa sobre igualdade entre todos os seres humanos, independente de qualquer diferença (ARTIGO QUINTO, 2019).

A lei diz que: Art. $5^{\circ}$ Todos são iguais perante a lei, sem distinção de qualquer natureza, garantindo-se aos brasileiros e aos estrangeiros residentes no País a inviolabilidade do direito à vida, à liberdade, à igualdade, à segurança e à propriedade, nos termos seguintes: I - homens e mulheres são iguais em direitos e obrigações, nos termos desta Constituição (BRASIL, 1988). 
Observa-se a realidade muito aquém do desejado, ainda é muito comum atestar os efeitos do machismo e do desprezo social pela independência feminina, nas falas e no comportamento do brasileiro. Socialmente, atitudes e transgressões masculinas são mais aceitas socialmente do que as femininas. Um homem que comete adultério não sofre os mesmos bloqueios sociais que as mulheres, da mesma forma, a mulher que decide deixar o lar sofre um julgamento descabido e desproporcional perto do julgamento que o homem sofre, já que sob o pensamento conservador, é a mulher quem deve tornar o lar um ambiente agradável para o marido, mais uma forma de transferir as responsabilidades do homem (BARROS AT e BUSANELLO E, 2019).

Influencia consideravelmente outra reprovação social que pesa mais sobre as mulheres, quando o homem a abandona na descoberta da gravidez, e quando a mulher resolver interromper a gestação pelo motivo do abandono paternal. É uma questão delicada e recorrente, já que não passa pelas discussões e sequer pode ser tocada como alternativa, tonar direito da mulher não dar continuidade a uma gestação, contudo, é de tamanha agressividade penalizar criminalmente uma mulher que interrompe a gestação e não tornar mais rígida a legislação que pune homens pelo abandono. De mesmo modo, há que se considerar que a criminalização do aborto atinge apenas mulheres pobres, que não aportam recursos financeiros suficientes para realizar 0 ato de maneira segura (BARROS AT e BUSANELLO E, 2019).

Se tornou uma necessidade urgente, educar os jovens para que não sejam um empecilho na luta por direitos iguais. É a maneira mais eficaz no combate ao conservadorismo, que causa tanto desgaste a mulher. Foi tão simples responsabilizar as mulheres pelo sofrimento que as mesmas passam e até mesmo as infelicidades masculinas, que se tornou cômodo dispensar a responsabilidade da luta por igualdade de gênero somente a elas. Não se fala com o mesmo fulgor da responsabilidade masculina no combate ao machismo, que é educar os próprios homens para que a violência não seja propagada (MINAYO MCS, 2005).

\section{CONSIDERAÇÕES FINAIS}

Compreende-se, portanto, que o problema da evasão escolar causada pela gravidez na adolescência, é a reunião de inúmeros problemas sociais que foram acumulados e não tratados ao longo do tempo. A solução ideal é a união de educação e saúde para instruir, educar e prevenir. Preparar as futuras gerações para não serem reprodutoras desse problema grave, é a alternativa ideal e uma forma e ampliar os cuidados com os casos já existentes. As instruções deverão acontecer tanto para meninos como para meninas, já que o problema central é causado por pessoas de ambos os sexos e requer a união da sociedade como um todo, construindo um ambiente saudável e colaborativo, onde condições de ser não pesem na construção do ser humano, onde devaneios sociais pretéritos não sigam causando problemas sociais graves e distanciamento humano de uma nova realidade mais benéfica.

\section{REFERÊNCIAS}

1. ARTIGO QUINTO. 2019. In: Homens e mulheres são iguais em direitos e obrigações, nos termos desta Constituição. São Paulo.

2. BARROS AT e BUSANELLO E. Machismo discursivo: modos de interdição da voz das mulheres no parlamento brasileiro. Revista Estudos Feministas, 2019; 27(2): 1-8.

3. BRASIL. 2007. In: CÂMARA DOS DEPUTADOS.

4. 1988. Constituição da República Federativa do Brasil: promulgada em 5 de outubro de 1988.

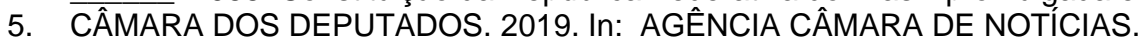

6. CARDOSO MLM, et al. A Política Nacional de Educação Permanente em Saúde nas Escolas de Saúde Pública: reflexões a partir da prática. Ciência \& Saúde Coletiva, 2017; 22(5): 1489-1500.

7. CARVALHO MP. Sucesso e fracasso escolar: uma questão de gênero. Educação e Pesquisa, 2003; 29(1): 185193.

8. CASTRO ABC, et al. Gênero, patriarcado, divisão sexual do trabalho e a força de trabalho feminina as sociedade capitalista. VI seminário CETROS. 2018; 2(6): 2-15.

9. CHACHAM AS, et al. Autonomia, gênero e gravidez na adolescência: uma análise comparativa da experiência de adolescentes e mulheres jovens provenientes de camadas médias e populares em Belo Horizonte. R. bras. Est. Pop, 2012; 29(2): 389-407.

10. DINIS N, ASINELLI-LUZ A. Educação sexual na perspectiva histórico-cultural. Educar, 2007; 30(1): 77-87.

11. EW RAS, et al. Diálogos sobre sexualidade na escola: uma intervenção possível. Psicologia em pesquisa, 2017 ; 11(2): 51-60. 
12. FACCHINI R, SÍVORI H. Conservadorismo, direitos, moralidades e violência: situando um conjunto de reflexões a partir da Antropologia. Cadernos Pagu, 2017; 22(1): 1-7.

13. FAIAL LCM, et al. A saúde na escola: percepções do ser adolescente. Revista Brasileira de Enfermagem, 2019; 72(4): 964-972.

14. MENESES C, et al. Transtornos mentais comuns em adolescentes grávidas: um estudo piloto. Revista Oficial do Núcleo de Estudos da Saúde do Adolescente/UERJ, 2008; 5(1): 50-56.

15. MINAYO MCS. Laços perigosos entre machismo e violência. Ciência \& Saúde Coletiva, 2005; 10(1): 23-26.

16. OMS. 2018. In: América Latina e Caribe têm a segunda taxa mais alta de gravidez na adolescência no mundo. Genebra-SUI: OPAS Brasil.

17. PICCININI CA, et al. Responsividade materna em famílias de mães solteiras e famílias nucleares no terceiro mês de vida da criança. Estudos de Psicologia; 12(2): 109-117.

18. PRÁ JR, EPPING L. Cidadania e feminismo no reconhecimento dos direitos humanos das mulheres. Revista Estudos Feministas, 2012; 20(1): 33-51.

19. SOUSA CRO, et al. Fatores preditores da evasão escolar entre adolescentes com experiência de gravidez. Cadernos Saúde Coletiva, 2018; 26(2): 160-169.

20. VERAS T. O Sistema Nacional de Combate ao Abuso e à Exploração Sexual Infantojuvenil e o Plano Nacional: um exemplo de política pública aplicada. Cadernos EBAPE.BR, 2010: 8(3): 404:421.

21. VIEIRA MC, CRUZ KN. A produção sobre a educação da mulherna educação de jovens e adultos. Revista do Centro de Educação, 2017; 42(1): 1-10. 